\title{
Rural-urban Migration and Urbanization in Gansu Province, China: Evidence from Time-series Analysis
}

\author{
Haiying Ma (Corresponding author) \\ Lecturer, School of Economics, Northwest University for Nationalities \\ Lanzhou 730124, China \\ E-mail: 1xmahaiying8888@163.com
}

Lina Lian

Associate professor, School of Economics, Northwest University for Nationalities

Lanzhou 730124, China

E-mail: jjlln@xbmu.edu.cn

$\begin{array}{lrr}\text { Received: June 9, } 2011 & \text { Accepted: July 10, } 2011 \quad \text { Published: December 1, } 2011 \\ \text { doi:10.5539/ass.v7n12p141 } & \text { URL: http://dx.doi.org/10.5539/ass.v7n12p141 }\end{array}$

\begin{abstract}
Urbanization is one of the hot issues in research at present. Since "go west", urbanization level in Gansu province has undergone significant change along with the largest flow of rural-urban migration around the country. This paper aims to attempt to examine projections of Gansu's urbanization level in 1990-2008 and analyze long-run impact of urbanization construction on rural-urban migration wage income in Gansu province, finally the paper empirically investigate dynamic effect of urbanization construction on rural-urban migration wage income with time series data. The results show that urbanization rate in Gansu displays quadratic function model, and relationship between urbanization rate and rural-urban migration wage income shows not only significant but also stable in the long-run.
\end{abstract}

Keywords: Rural-urban migration, Urbanization rate, Time series analysis

\section{Introduction}

Since the reform and opening-up, china has experienced enormous development in agriculture and rural economy. As a result, the rural-urban migration around the country occurred and evolved along with the process of urbanization. The migration of rural labor force to urban areas is an inevitable trend in the process of economic growth and social development. With the acceleration of the process, more and more surplus labor force gradually diverted to engage in non-agricultural sectors. Rural migrant workers become a strong new labor force emerging along with the urbanization through the centralization of population, and it is the main source of urbanization growth in China. A large body of literature has examined the relationship between rural-urban migration and urbanization. The classical theory of migration and urbanization was initially developed by Lewis (1955), the core of the theory is the dual economy model. The theory takes rural-urban migration as the equilibrium mechanism of surplus labor, which withdrawn labor from the rural sector with almost zero marginal productivity to modern urban sectors with approaching full employments. Therefore, output growth, trend acceleration, and rising migration and urbanization are likely outcomes of the labor surplus model. The most influential model of the rural-urban migration was introduced by Todaro (1969). The model stated that rural-urban migration not only depends on urban-rural differences in expected income rather than actual earnings but also on the various labor market opportunities available to them in the rural and urban sectors. The model predicts that migration rates in excess of urban job opportunity growth rates are possible and rational. It is generally recognized economic development and income differentials of rural-urban are the most important determinant of rural surplus labor migration Wang (1997). It also impact significantly on urban population growth, many empirical studied have proved it, including Zhang (2002). Some researcher focused on the "pull" effect of the urban and concluded that industry foundation of urbanization lies on urban industry as well as service development Hong and Cheng (2000) Liu, et al (2003) examined the urbanization-level by The S-curve 
Regression Model and stated that urbanization-level in China in 2010 is $40.03 \%$, and estimated that in 2020 and in 2030 , it will be $50.14 \%$ and $57.24 \%$ respectively. Meanwhile, the urbanization-level in Gansu province is also estimated by the same model, it is $30.75 \%$ in $2010,37.37 \%$ in 2020 and $44.5 \%$ in 2030 respectively. Zhu (2003) advocated that education plays the very important role in the process of urbanization. Under the background of transformation of economic structure and promotion of industry structure, high education effectively relax the conflict between the over-crowded low level labor market and the low level of marginal production, and drive the stable development of rural surplus labor force. Wang (2002) found that degree of education, among different factors pushing surplus labor in the process of urbanization, plays dominating role, the most-intended to urbanization are those who are junior high-school certificate holder. Most studies, however, forces on the relations at the national level, or big city and developed areas. In China, urbanization is generally defined as the convergence process of population to urban areas, and measured by the indictor of urbanization-level, which is the ratio of urban population to the total population in a region or a county (X. Xu, et al, 1999).

As one of the inland and less developed region in west China, Gansu's urbanization has substantially lagged behind its economic growth. However, the rural-urban migration influences the healthy development of urbanization, the fundamental solution of the "three-dimensional rural issues" (concerning agriculture, countryside and farmers), and the realization of social equality, fairness and harmony. The local government places high importance on the migration of surplus rural labor force, and has made significant achievements in guiding the rural labor force migrate to non-agricultural sectors and urban areas. In the existing literature, there are few studies focusing on inland areas like Gansu, and no studies can be found to projections of Gansu's urbanization level. The objective in this paper is to examine the projections of Gansu's urbanization level in 1990-2008 by quadratic function model. The rest of this paper is organized as follow: section 2 presents data and methodology used in the paper. Section 3 analyzes long-run impact of urbanization construction on rural-urban migration wage income in Gansu. Section 4 empirically investigates dynamic effect of urbanization construction on rural-urban migration wage income with time series data. The last section is the conclusion and implications.

\section{Data and Methodology}

\subsection{Data}

The main economic indicators used to measure urbanization level in empirical study are: population density, non-agriculture population, GDP ect. However, the most important one is urbanization rate (UPR), which can be defined as the percentage of urban population out of total populations. In this paper, the number of rural-urban migration (RUM)1996-2008 can be found from the Labor Affairs Office, People's Government Gansu, and the number from 1990 to 1995 can be utilized by the research project by Wang (2007 Gansu Academy of Social Sciences). Total population (TP), urban population (UP) and income from wage (WI) in Gansu province are obtained from the various Gansu Yearbook.

\subsection{Methodology}

In order to avoid spurious regression situation, all variables in a regression model must be stationary or co-integrated. However, several empirical studies concluded that many macroeconomic time series data are non-stationary, both UPR and RUM in this paper, for instance. The augmented Dickey-Fuller test (ADF) (Dickey \& Fuller, 1979) is a test for a unit root in a time series sample. It's the augmented version of the Dickey-Fuller (DF) test for resolving the existence of autocorrelations phenomenon. It's also a larger and more complicated set of time series models, and it indicates the error term is not white noise. ADF test is the parametric approach and considers the intercept and time trend. The paper carries out the co-integration test to examine whether there is a cause-and-effect relationship between UPR and RUM in Gansu. If the two series variables are found to be co-integrated, then we retrieve the error correction term from the co-integrating equation and test the direction of causation. If the two variables are not co-integrated, then we employ Granger's causality to test the direction of short-run causation.

\section{Empirical Analysis}

\section{1 projections of Gansu's urbanization level}

In order to examine the urbanization rate in Gansu province, we collect the data of total population and urban population from Gansu yearbook 2009, as shown in table. Therefore, UPR can be easily calculated.

The UPR in table 1 shows that urbanization rate in Gansu province was $22.04 \%$ in 1990, and in 2008, this rate reached $32.15 \%$. In other words, the average growth rate of urbanization in Gansu province was 1.36 times in 2008 than that of in 1990, or the annual average growth rate was $1.95 \%$. Therefore, we can obtain the following quadratic model with regard to time series data. 


$$
\begin{aligned}
& \mathrm{UPR}=17773.65-1.78 * \mathrm{~T}+0.0004467 * \mathrm{~T} 2 \\
& \begin{array}{lll}
\mathrm{T}=(5.899) & (-5.913) & (5.928) \\
\mathrm{R}^{2}=0.949 & \mathrm{~F}=121.363 & \mathrm{D}-\mathrm{W}=0.4539
\end{array}
\end{aligned}
$$

The statistics of the model is significant to state that the model fit the perfect goodness. By using the above model we can acquire projections of urbanization rate in various years, and graph both projections and actual value in figure 1. It is clear to see from the figure that goodness of the model fit well to urbanization rate in Gansu province and also shows stable growth.

\subsection{Long-run impact of urbanization construction on migration's wage income}

According to the UPR and WI in the table 1, we can analyze the long-run impact of urbanization construction on migration's wage income. Therefore, the co-integration test can be used to examine the long run or equilibrium relationship between the variables of URP and WI. The results of the co-integration is summarised in table 2, where $\mathrm{d}$ stands for growth rate. It provides evidence to reject the null of zero co-integrating vectors in favour of one co integrating vector at the $5 \%$ level of significance. It is also easy to see that dupr, LOGdupr and dwi are integrated processes of order I (1) respectively and LOGdwi is integrated processes of order I (0). The test statistics suggests that there exists a long equilibrium relationship between URP and WI in Gansu province.

If the variables are co integrated, the adequate method to examine the causal relations is the Vector Error Correction Model (VECM) (Granger, 1988); otherwise a VAR model is used in the case of no co integration found among the variables (Granger, 1969). The standard Granger Causality Test (GC) test then examines if there exists feedback (bi-directional) or one-way causality between variables. The results of the GC test are shown in Table 3. They indicate that a zero hypothesis that urbanization rate does not influence WI can be rejected which implies adoption of the opposite hypothesis, i.e., that urbanization rate affects WI.

\subsection{Dynamic effect of urbanization construction on migration's wage income}

In order to analyze dynamic relationship between urbanization constructions and rural-urban migration wage income, it is possible to develop a model that can test the long-run relationships between urbanization and migration's wage income by integrating the concepts of co-integration and Granger causality. The model is known as the error correction model proposed by Engle and Granger (1987). An error correction model (ECM) is used to test for intermporal causality between these variables. In our model, $\varepsilon_{4 t}$ represents error series $\mu_{4}$ in the process of co-integration, $\mathrm{D}(\mathrm{dwi})$ is dependent variable, we introduce $\varepsilon_{4 t}(-1), \mathrm{D}(\mathrm{dwi})(-1)$, LOG(dupr), LOG(dupr)(-1), LOG(dupr)(-2), LOG(dupr)(-3) one by one and remove insignificant variable, the following model can be obtained.

$$
\begin{gathered}
\mathrm{D}(\mathrm{dwi})=0.062-0.4315 * \mathrm{D}(\mathrm{dwi})(-1)+1.94 * \varepsilon_{4 t}(-1)+0.498 * \mathrm{LOG}(\text { dupr })(-2)+0.195 * \mathrm{LOG}(\mathrm{dupr})(-3) \\
\mathrm{T}=\left(\begin{array}{ccc}
(-2.5901) & (-5.4965) & (7.43) \\
& \mathrm{R}^{2}=0.966
\end{array} \quad \mathrm{D}-\mathrm{W}=2.0963\right.
\end{gathered}
$$

Replacing error correction item $\varepsilon_{4 t}(-1)=\mathrm{dwi}(-1)+0.04528 * \mathrm{LOG}(\mathrm{dupr})(-1)$ to equation 1 , we can get:

$$
\begin{gathered}
\mathrm{D}(\mathrm{dwi})=0.062-0.4315 * \mathrm{D}(\mathrm{dwi})(-1)+1.94 * \varepsilon_{4 t}(-1)+0.498 * \mathrm{LOG}(\mathrm{dupr})(-2)+0.195 * \mathrm{LOG}(\mathrm{dupr})(-3)+1.94 * \\
(\mathrm{dwi}(-1)+0.04528 * \operatorname{LOG}(\mathrm{dupr})(-1))
\end{gathered}
$$

Equation 2 indicates that dwi and LOG (dupr) is the error correction model of two time series, reflecting dynamic relationship between two variables, and $-0.4315,-0.498,-0.195$ shows the relationship in short run of the variables. While 0.04528 in the model shows the long-run indicator.

\section{Conclusions and Discussions}

This paper contributes an analysis of the linkage between UPR and WI in Gansu province, China. First, the projections of Gansu's urbanization level in 1990-2008 are examined. Second, based on the co-integration results, it indicates that there exists a long equilibrium relationship between UPR and WI. Third, through the error correction coefficient, it implies that the assumption that WI impels UPR is false. Finally, it investigates dynamic effect of urbanization construction on rural-urban migration wage income with time series data.

Due to the existing large amount of surplus rural labor force and huge rural-urban disparity in income and living standards, the potential pushing forces of urbanization and rural-urban migration in Gansu would remain strong for a rather long period. This paper intends to address factors behind the Gansu's process of migration and urbanization based on both time-series. Some policy implications regard rural-urban migration and urbanization may be drawn from this study. First, the sound urban structure in Gansu province should be formatted, the author in this paper thinks that scale of urban structure can be expanded as a whole. At the same time, classified 
construction should be made according to the inner differentials. Wang (1999) showed that the most net return of scale was between one million to four million of urban populations. In Gansu, only few cities occupy population more than one million. Therefore, expanding the urban scale in Gansu is a core principle so as to insure the cityward migration. Second, local government should pay more attention to establish and implement three-dimension strategy of agriculture industrialization, development of township-owned enterprises and small town constructions. According to comparative advantage theory, the process of township-owned enterprises implies mainly the process of agriculture industrialization. Sound distribution and centralized planning of township-owned enterprises in turn impel those enterprises to central in urban. As a result, three-dimension strategy of agriculture industrialization, development of township-owned enterprises and small town constructions in Gansu can be formatted. Third, the reform of hukou system should be speed up so as to eliminate the urban- rural barrier. The traditional dual economy structure and the hukou system confine the rural surplus labor to migrate to urban sectors, and the urbanization level lags behind the economic growth. Therefore, it is urgent to break down the old hukou system and reduce threshold of entering urban areas. Four, reducing the rural-urban income gap may be a powerful policy instrument to control the pace of migration and urbanization. Because migrants respond significantly to differentials between the rural and urban income, it is vitally important that imbalances between economic opportunities in rural and urban areas should be minimized.

\section{References}

Chang, H. G., \& Brada, J. C. (2002). China's urbanization lag during the period of reform: A paradox. Working Paper. University of Toledo and Arizona State University.

Corden, W., \& Findlay, R. (1975). Urban unemployment, intersectoral capital mobility and development policy. Economica, 42, 59-78. http://dx.doi.org/10.2307/2552986

Fei, J. C. H., \& Ranis, G. (1964). A theory of economic development. American Economic Review, 51, 533-565.

Hare, D. (1999). 'Push' versus 'pull' factors in migration outflows and returns: Determinants of migration status and spell duration among China's rural population. Journal of Development Studies, 35(3), 45-72. http://dx.doi.org/10.1080/00220389908422573

K. H zhang \& S song. (2003). Rural-urban migration and urbanization in China:Evidence from time-series and cross-section analyses. China Economic Review, 14, 386-400.

Knight, J., \& Song, L. (1999). The rural-urban divide: Economic disparities and interactions in China. Oxford: Oxford University Press.

Song, S. (2001). City size and urban unemployment: Evidence from China. World Economy and China, 9(1), 46-53.

Xu, X.Q., Zhou Y.X. and Ning Y.M. (1999). Urban Geography. Beijing: Higher Education Press, 43.

Wang, F., \& Zuo, X. (1999). Inside China's cities: Institutional barriers and opportunities for urban migrants. American Economic Review: Papers and Proceedings, 89(2), 276-280. http://dx.doi.org/10.1257/aer.89.2.276

Table 1. Results of projections of Gansu's urbanization level: 1990-2008

TP \& UP: 10,000; UPR: \%; WI: RMB

\begin{tabular}{cccccccccc}
\hline year & TP & UP & UPR & WI & year & TP & UP & UPR & WI \\
\hline 1990 & 2254.67 & 496.93 & 22.04 & 14.78 & 2000 & 2556.89 & 613.91 & 24.01 & 355.03 \\
\hline 1991 & 2284.92 & 508.62 & 22.2 & 15.54 & 2001 & 2575.24 & 631.19 & 24.51 & 405.99 \\
\hline 1992 & 2314.19 & 520.46 & 22.49 & 15.88 & 2002 & 2592.58 & 673.03 & 25.96 & 447.41 \\
\hline 1993 & 2345.23 & 532.6 & 22.71 & 73.97 & 2003 & 2603.34 & 712.79 & 27.38 & 488.73 \\
\hline 1994 & 2378.25 & 545.57 & 22.94 & 81.89 & 2004 & 2618.78 & 749.23 & 28.61 & 527.68 \\
\hline 1995 & 2437.95 & 564.87 & 23.19 & 91.68 & 2005 & 2594.36 & 778.83 & 30.02 & 586.71 \\
\hline 1996 & 2466.86 & 577.99 & 23.43 & 146.78 & 2006 & 2606.25 & 810.28 & 30.45 & 632.23 \\
\hline 1997 & 2494.2 & 590.88 & 23.69 & 190.95 & 2007 & 2617.16 & 826.76 & 31.23 & 678.63 \\
\hline 1998 & 2519.37 & 600.62 & 23.84 & 235.87 & 2008 & 2628.12 & 844.94 & 31.89 & 724.32 \\
\hline 1999 & 2542.58 & 612 & 24.07 & 298.62 & & & & & \\
\hline
\end{tabular}

Source: Gansu Yearbook 
Table 2. The results of co-integration test

\begin{tabular}{cccc}
\hline variables & ADF test types $\left(\mathrm{C}, \mathrm{T},{ }^{*}\right)$ & T statistics & 5\% critical value \\
\hline dupr & $(\mathrm{C}, 0,0)$ & -0.8106 & -3.0988 \\
\hline LOG(dupr) & $(\mathrm{C}, 0,2)$ & -1.8658 & 3.1449 \\
\hline dwi & $(\mathrm{C}, 0,1)$ & -0.2244 & -3.2126 \\
\hline LOG(dwi) & $(\mathrm{C}, 0,3)$ & -3.3254 & -3.1753 \\
\hline $\mathrm{D}($ dupr $)$ & $(0,0,0)$ & -2.9205 & -1.9709 \\
\hline $\mathrm{D}(\mathrm{LOG}($ dupr $))$ & $(0,0,2)$ & -3.5093 & -1.9777 \\
\hline $\mathrm{D}($ dwi $)$ & $(0,0,2)$ & -3.5784 & -2.0211 \\
\hline
\end{tabular}

Table 3. Granger Causality Test

\begin{tabular}{cccc}
\hline hypothesis & Observations & F statistics & Probability \\
\hline dupr does not Granger Cause dwi & 13 & 2.4085 & 0.1517 \\
\hline dupr does not Granger Cause LOGdwi & 13 & 6.0896 & 0.0247 \\
\hline LOGdupr does not Granger Cause dwi & 13 & 6.335 & 0.0425 \\
\hline LOGdupr does not Granger Cause LOGdwi & 13 & 8.5079 & 0.0245 \\
\hline
\end{tabular}

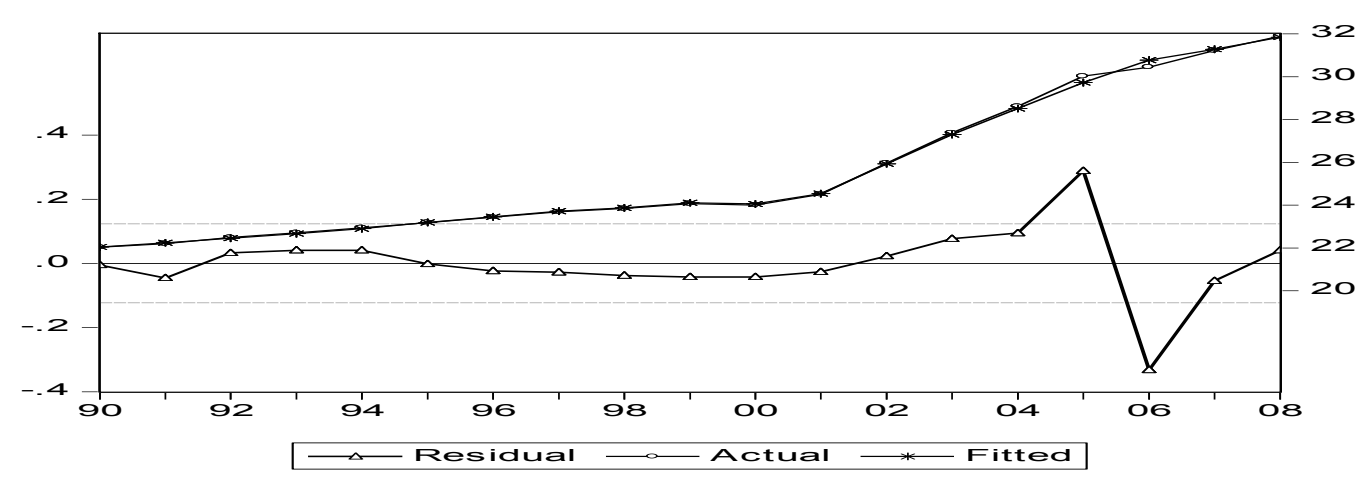

Figure 1. Actual and fitted value of urbanization rate in Gansu province 